\title{
Fontanelle Depressed
}

National Cancer Institute

\section{Source}

National Cancer Institute. Fontanelle Depressed. NCI Thesaurus. Code C116898.

Membranous areas between cranial bones in a newborn that appear depressed or sunken. 